\title{
Oncologic Resection Achieving R0 Margins Improves Disease-Free Survival in Parathyroid Cancer
}

\author{
K. M. Schulte, MD, FRCS ${ }^{1,8}$, N. Talat, BSc (Hons) ${ }^{1}$, G. Galata, MD ${ }^{1}$, J. Gilbert, PhD $^{2}$, J. Miell, FRCPE, FRCP ${ }^{4}$, \\ L. C. Hofbauer, $\mathrm{MD}^{5}$, A. Barthel, $\mathrm{MD}^{6}$, S. Diaz-Cano, MD, PhD, FRCPath ${ }^{3}$, and S. R. Bornstein, MD, PhD ${ }^{6,7}$ \\ ${ }^{1}$ Department of Endocrine Surgery, King's College Hospital, King's Health Partners, King's College London, London, \\ UK; ${ }^{2}$ Department of Endocrinology, King's College Hospital, King's Health Partners, London, UK; ${ }^{3}$ Department of \\ Histopathology, King's College Hospital, King's Health Partners, London, UK; ${ }^{4}$ Department of Endocrinology, University \\ Hospital Lewisham, London, UK; ${ }^{5}$ Diabetes and Bone Diseases, Dresden Technical University Medical Centre, Dresden, \\ Germany; ${ }^{6}$ Department of Medicine III, Dresden Technical University Medical Centre, Dresden, Germany; ${ }^{7}$ Department of \\ Diabetes and Endocrinology, King's College London, London, UK; ${ }^{8}$ Department of Surgery, John Curtin School of \\ Medical Research, Australian National University, Canberra, Australia
}

\begin{abstract}
Background. Parathyroid cancer has a poor mid-term prognosis, often because of local recurrence, observed in half of all patients. Modern diagnostic workup increasingly enables a preoperative diagnosis of parathyroid cancer. There is limited evidence that more comprehensive oncologic surgery can reduce the risk of local recurrence. This study aims to identify the best specific surgical approach in parathyroid cancer.
\end{abstract}

Methods. This observational cohort study comprises 19 consecutive patients who had undergone oncologic or nononcologic resection for parathyroid cancer. Baseline parameters were compared by using univariate analysis; outcomes were assessed by $\chi^{2}$ testing and Kaplan-Meier statistics. Results. Fifteen of 19 patients were primarily operated on in our tertiary center between 1996 and 2013, and four were referred for follow-up because of their cancer diagnosis. Patient cohorts defined by histologic R-status were comparable for established risk factors: sex, calcium levels, lowrisk/high-risk status, and presence of vascular invasion. Oncologic resections were performed in 13 of 15 patients primarily treated in the center and 0 of 4 treated elsewhere $\left(\chi^{2}=5.6 ; p<0.01\right)$. R0 margins were achieved in 11 of 13 (85\%) undergoing oncologic resection and 1 of $6(17 \%)$ undergoing local excision $\left(\chi^{2}=8.1 ; p<0.01\right)$. R0 margins

(C) Society of Surgical Oncology 2014

First Received: 18 November 2013;

Published Online: 13 February 2014

K. M. Schulte, MD, FRCS

e-mail: klaus-martin.schulte@nhs.net and primary oncologic resection were associated with higher disease-free survival rates $\left(\chi^{2}=7.9 ; p=0.005\right.$ and $\chi^{2}=4.7 ; \quad p=0.03$, respectively). Revision surgery achieved R0 margins in only 2 of $4(50 \%)$ of patients.

Conclusions. In parathyroid cancer, a more comprehensive surgery (primary oncologic resection) provides significantly better outcomes than local excision as a result of reduction of R1 margins and locoregional recurrence.

Parathyroid cancer accounts for approximately 1-2\% of cases of primary hyperparathyroidism. ${ }^{1,2}$ It has a poor prognosis, with a 10-year survival rate of $<50 \%$. ${ }^{3}$ Recurrence after surgery has been reported in more than $50 \%$ of patients, and local recurrence accounts for at least half of these cases. ${ }^{4,5}$ Recent advancements in genetic, biochemical, and biophysical work-up allow for a reliable preoperative identification of lesions at risk of being parathyroid cancer. ${ }^{6}$ A high index of suspicion is warranted for lesions larger than $3 \mathrm{~cm}$ or presenting with a corrected calcium $>3.0 \mathrm{mM}^{6}{ }^{6}$ Ultrasonography helps with preoperative recognition of cancer, as does a high ratio of third- over second-generation parathyroid hormone (PTH) assays. $^{7-10}$ Although it should hence be possible to at least suspect the diagnosis of parathyroid cancer, most patients with parathyroid cancer yet undergo nononcologic forms of resection, such as local excision of the lesion alone. ${ }^{4,6}$

Although theoretically well founded, there is little direct published evidence supporting the approach of oncologic resection besides a retrospective review. ${ }^{4}$ Also, there is limited evidence that achieving an $\mathrm{R} 0$ resection has beneficial effect on outcome. ${ }^{11}$ On the basis of our review of the literature and our own experience, we have defined surgical 




FIG. 1 The two main histologic criteria of malignancy in parathyroid neoplasms are the evidence of stromal invasion with extraglandular extension (a hematoxylin-eosin (HE) $\times 12.5$, b $\mathrm{HE}$ $\times 40)$ and the presence of vascular invasion $(\mathbf{c ~ H E} \times 200, \mathbf{d ~ H E} \times 400)$. The invasion is histologically demonstrated by desmoplastic reaction

resection types and prospectively performed well-defined oncologic resections in all patients with suspected parathyroid cancer. ${ }^{4,6,12}$ This study compares outcomes of this small and well- documented cohort with those of a cohort of patients with local excision only, referred to us for follow-up in the face of the cancer diagnosis.

\section{PATIENTS AND METHODS}

A cohort of 19 consecutive patients with a histologic diagnosis of parathyroid cancer was analyzed retrospectively in our tertiary endocrine surgical center between 1996 and 2013. One patient treated at the center was operated on in 1996 by another surgeon (Appendix Table 4). Four patients underwent surgery as local excision alone elsewhere and were referred in view of the cancer diagnosis. None of them had manifest persistent disease at the time of referral. Three of these patients developed locoregional recurrence and underwent reoperation. Fourteen parathyroid cancer patients were primarily operated on by the lead author (K.-M.S.) between 2005 and 2013 (Appendix Table 4). Cancer had been suspected in all but one patient, and 13 patients underwent oncologic resection with en-bloc removal of the parathyroid lesion with surrounding fat tissue, ipsilateral thyroid lobe, and

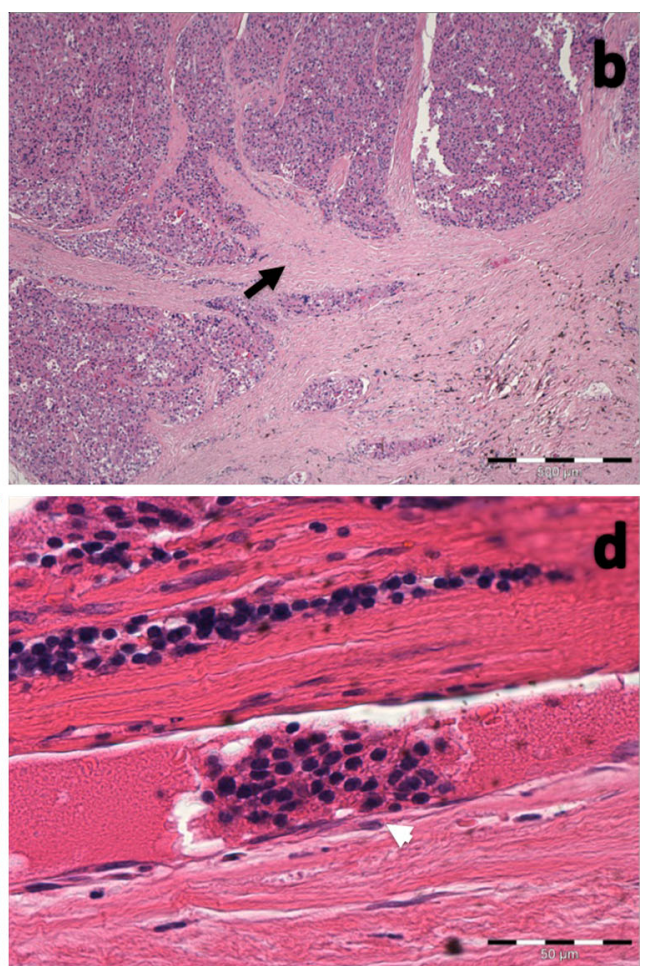

and broad fibrous bands of at least 1 microscopic high-power field (arrows), and the vascular invasion is identified by intravascular tumor cells embedded in fibrinous material or directly attached to endothelial cells (arrowheads)

level VI lymph nodes (Appendix Table 5). In the earlier part of the series, the ipsilateral lateral lymph nodes were also included. A total of 221 lymph nodes were excised in 19 patients, of which 111 of 221 were from the central compartment of level VI and 110 of 221 were from levels II to V (Appendix Table 5). The recurrent laryngeal nerve was included in the resection in 4 patients $(28 \%)$ because it was visibly involved by the cancer and could not be spared without risk of disrupting the integrity of the specimen margins (Appendix Table 5). One patient presented with a corrected calcium of $3.0 \mathrm{mM}$ and a lesion of only $22 \mathrm{~mm}$ (Appendix Table 4). She was not suspected to have cancer and underwent local excision alone (Appendix Table 5). One patient out of the 14 mentioned previously developed locoregional recurrence and underwent reoperation.

Surgical intervention was defined as previously ${ }^{6,13}$ : local excision only, i.e., pericapsular excision of the parathyroid lesion such as usually used for benign lesions, and en-bloc excision, which includes en-bloc and oncologic resection. En-bloc describes excision of the parathyroid with circumferential soft tissue as the minimal criterion; in this process, the tumor capsule must not be laid open at any point. Oncologic resection additionally includes ipsilateral thyroid lobectomy, Centro cervical lymphadenectomy of level VI lymph nodes, and/or further locoregional excision. 
TABLE 1 Univariate analysis comparing cohorts undergoing R0 and $\mathrm{R} 1$ resection

\begin{tabular}{|c|c|c|c|}
\hline Clinical factors & $\mathrm{R} 0(n=12)$ & $\mathrm{R} 1(n=7)$ & $\overline{\chi^{2}(p \text { Value })}$ \\
\hline \multicolumn{4}{|l|}{ Gender } \\
\hline Male/female & $3 / 9$ & $2 / 5$ & NS \\
\hline \multicolumn{4}{|l|}{ Age (years) } \\
\hline Mean \pm SD & $53.1 \pm 11.3$ & $65.7 \pm 9.5$ & $6.0(0.02)$ \\
\hline Median & 57.5 & 59.0 & \\
\hline Range & $33.0-67.0$ & $54.0-81.0$ & \\
\hline \multicolumn{4}{|l|}{$\mathrm{PTH}^{\mathrm{a}} n g / \mathrm{L}$} \\
\hline Mean \pm SD & $9.5 \pm 8.0$ & $7.1 \pm 5.0$ & NS \\
\hline Median & 4.7 & 5.7 & \\
\hline Range & $1.5-22.3$ & $1.3-13.7$ & \\
\hline \multicolumn{4}{|l|}{ Calcium $^{\mathrm{a}} \mathrm{mM}$} \\
\hline Mean $\pm \mathrm{SD}$ & $3.1 \pm 0.6$ & $3.1 \pm 0.3$ & NS \\
\hline Median & 2.8 & 2.9 & \\
\hline Range & $2.8-4.7$ & $2.7-3.6$ & \\
\hline \multicolumn{4}{|l|}{ Size of lesion $(\mathrm{mm})$} \\
\hline Mean $\pm \mathrm{SD}$ & $38.7 \pm 17.4$ & $32.7 \pm 14.7$ & NS \\
\hline Median & 35.0 & 30.0 & \\
\hline Range & $15.0-65.0$ & $20.0-56.0$ & \\
\hline \multicolumn{4}{|l|}{ Vascular invasion } \\
\hline Yes/no & $6 / 6$ & $4 / 3$ & NS \\
\hline \multicolumn{4}{|c|}{ Lymph node metastases } \\
\hline Yes/no & $0 / 11^{\mathrm{b}}$ & $1 / 1^{\mathrm{c}}$ & NS \\
\hline \multicolumn{4}{|l|}{ Histology } \\
\hline Low risk/high risk & $6 / 6$ & $4 / 3$ & NS \\
\hline
\end{tabular}

$N S$ not statistically significant

${ }^{a}$ Fold elevated: Calculated as times the upper normal limit of the method used

${ }^{\mathrm{b}}$ Lymph node dissection was not done in 1 patient

${ }^{c}$ Lymph node dissection was not done in 5 patients

Histologic diagnosis and resection margins were defined by World Health Organization criteria ${ }^{14}$ (Fig. 1): R0, no cancer cells at the margins; and R1, cancer cells at the edge of the histologic specimen or resection within less than $1 \mathrm{~mm}$ of the edge.

Patients were also classified as low risk or high risk according to the validated parathyroid cancer classification scheme described previously ${ }^{12}$ : low risk, capsular invasion combined with invasion of surrounding tissue only; and high risk, vascular invasion and/or lymph node metastases and/or invasion of vital organs and/or distant metastases.

Follow-up of patients was achieved through a dedicated parathyroid cancer clinic obtaining levels of corrected calcium and PTH every 3 months. Imaging was obtained in the presence of biochemical signs of cancer recurrence. Histologic assessment confirmed locoregional recurrence in four of four patients $(100 \%)$ after reoperation.
TABLE 2 Surgery performed in cohorts with R0 and R1 resection

\begin{tabular}{lrll}
\hline Variable & R0 & R1 & $\chi^{2}(p$ Value $)$ \\
\hline Oncologic excision & 11 & 2 & $8.1(0.01)$ \\
Nononcologic excision & 1 & 5 &
\end{tabular}

Oncologic excision includes patients who underwent en-bloc resection. Nononcologic excision includes patients who underwent local resection only

Values for mean and median, $\chi^{2}$ test results, and Kaplan-Meier statistics were calculated by using SPSS software version 18.0.

\section{RESULTS}

A total of 19 patients were treated for parathyroid cancer: R0 resection was achieved in 12 of 19 (63\%), and 7 of 19 (37 \%) had an R1 resection (Table 1). Sex was equally distributed in both groups (Table 1). Patients with R0 resection were significantly younger than those with $\mathrm{R} 1$ resection $(53.1 \pm 11.3$ years vs. $65.7 \pm 9.5$ years; $p<0.02$; Table 1). Biochemically, patients with $\mathrm{R} 0$ resection had higher preoperative PTH levels, whereas calcium levels were similar in both cohorts (Table 1). Larger tumors were also noted in patients with $\mathrm{R} 0$ resection $(38.1 \pm 17.4 \mathrm{~mm}$ vs. $32.7 \pm 14.7 \mathrm{~mm}$ ); however, these differences were not statistically significant (Table 1). Histologically, no significant difference was observed between the two cohorts (Table 1). An oncologic surgical approach was common in patients with R0 resection (92\%), whereas $71 \%$ patients with R1 resection underwent nononcologic surgery (Table 2). Univariate analysis comparing patients with nononcologic and oncologic resection showed no significant difference in relation to these parameters except for age (Appendix Table 6). Recurrence-free survival was higher in patients who underwent oncologic surgery $(93 \%)$ compared with those with nononcologic excision (50\%; Fig. 2). Recurrence was not observed in any of the patients with R0 resection (0 of 12), whereas 5 of 7 (71\%) patients with R1 resection experienced locoregional recurrence (Fig. 2).

Of the five patients with recurrence, four had revision surgery, and R0 margins were achieved in only 2 of $4(50 \%)$ of these patients (Table 3). One patient is undergoing further investigation before repeat surgery can proceed (patient 15).

\section{DISCUSSION}

Parathyroid cancer is an infrequent but aggressive malignancy. Our results confirm the established knowledge of a high risk of locoregional recurrence in this form of cancer. ${ }^{4-6}$

Comparison of established risk factors for an adverse outcome in parathyroid cancer, i.e., male sex, preoperative corrected serum calcium levels, presence of vascular 


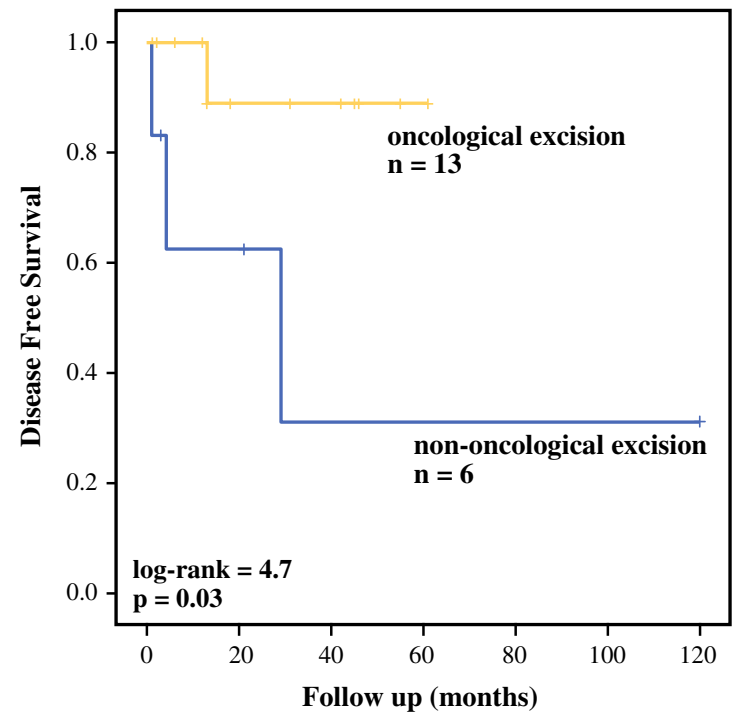

FIG. 2 Outcomes based on initial surgical approach and resection margin (left) $3 / 6$ patients $(50 \%)$ with non-oncological surgery suffered local recurrence of disease, whilst only one patient $(7 \%)$ in the oncological surgery cohort suffered both local recurrence, in his case combined with distant metastases. (right) None of the R0

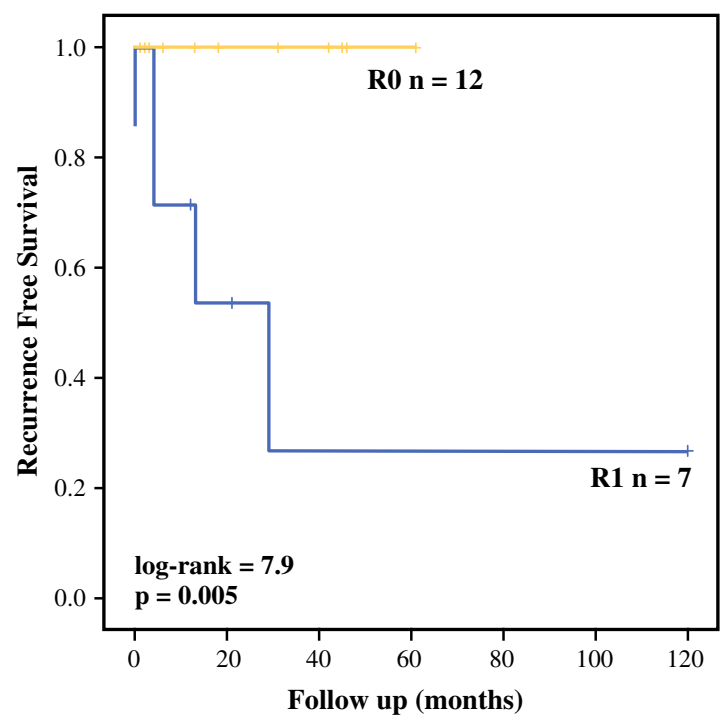

patients $(0 \%)$ had local recurrence, whilst $5 / 7$ of $\mathrm{R} 1$ patients $(71.4 \%)$ suffered local recurrence. Four of these patients were initially treated elsewhere with local excision only. One was treated at $\mathrm{KCH}$ with initial en bloc resection. The 2 patients with $\mathrm{R} 1$ resection who did not have recurrence underwent radiotherapy post-op

TABLE 3 Reoperations in patients with recurrent/persistent disease

\begin{tabular}{|c|c|c|c|c|c|c|c|c|c|}
\hline $\begin{array}{l}\text { Patient } \\
\text { No. }\end{array}$ & Reoperation $^{a}$ & $\begin{array}{l}\text { Resection } \\
\text { margin after } \\
\text { reoperation }\end{array}$ & $\begin{array}{l}\text { Adjuvant } \\
\text { therapy }\end{array}$ & $\begin{array}{l}\text { Overall follow-up } \\
\text { after reoperation } \\
\text { (months) }\end{array}$ & $\begin{array}{l}\text { Local } \\
\text { recurrence } \\
\text { after reoperation }\end{array}$ & $\begin{array}{l}\text { Distant } \\
\text { metastases }\end{array}$ & $\begin{array}{l}\text { Time to distant } \\
\text { metastases } \\
\text { (months) }\end{array}$ & $\begin{array}{l}\text { Death due } \\
\text { to disease }\end{array}$ & Histology \\
\hline 2 & LE & $\mathrm{R} 1$ & $\begin{array}{l}\mathrm{RT}(55 \mathrm{~Gy}, 20 \\
\text { fractions) }\end{array}$ & 42 & No & Yes & 58 & No & HR \\
\hline 17 & EB & R0 & Planned for RT & $5^{b}$ & No & No & - & No & HR \\
\hline 18 & LE & $\mathrm{R} 1$ & Planned for RT & 12 & No & No & - & No & HR \\
\hline 19 & EB & R0 & No & $5^{b}$ & No & No & - & no & LR \\
\hline
\end{tabular}

$R T$ radiotherapy, $H R$ high-risk histology, $L E$ local excision, $L R$ low-risk histology; $E B$ en bloc

Patient 2 was the only patient who experienced local recurrence out of the 14 patients treated at our center by K.-M.S. and was the only patient who developed systemic disease out of the 19 patients with parathyroid cancer

${ }^{a}$ Reoperation performed at our center by K.-M.S

${ }^{\mathrm{b}}$ Reoperation performed in July 2013

invasion, and risk status, did not vary significantly between patients with R0 and R1 resection. ${ }^{4,12}$ Tendentially, patients in whom an R0 resection was achieved had larger lesions and higher PTH levels. This observation makes it unlikely that poorer outcomes in the R1 group relate to more aggressive or more-difficult-to-remove lesions.

Local excision alone as opposed to oncologic resection resulted in a significantly higher risk of failing to achieve complete resection of the primary cancer lesion (Table 2). It was also associated with higher rates of locoregional recurrence and, accordingly, lower disease-free survival (Fig. 2). R1 resection was related to a decreased disease-free survival (Fig. 2).

In the biological context, these outcomes indicate that the poorer disease-free survival in patients undergoing local excision relates to recurrence from the residual R1 cancer tissue. The data also corroborate the claim that oncologic resection prevents locoregional recurrence by completely excising the primary tumor and lymph node metastases.

One limitation of this study is the small cohort size, which yet belongs to the largest published series in this rare entity. The study hence closes an important gap of previous cohort studies and registry studies, which do not disclose detail on R-status, exact surgical technique, or both, and their relation to outcome. ${ }^{3,5,15-18}$

Another potential cofounder is that all oncologic surgery was performed by one author (K.-M.S.), and outcome differences could hence be possibly accounted for expert versus nonexpert surgical skills. Follow-up in the R1 
resection group is longer than in the $\mathrm{R} 0$ resection group. However, the use of Kaplan-Meier statistics with the logrank test should account for these statistical issues.

The choice of oncologic surgical technique will remain to be further specified. Lymph node metastasis in level VI according to Robbins is not common but ranges from 4 to $65 \%$ where examined. ${ }^{3,12,13},{ }^{18-25}$ Because level VI dissection does not impose significant risk to the patient, it should, in our opinion, be an integral part of the procedure. The removal of the ipsilateral hemithyroid may be the easiest and safest way forward whenever the parathyroid touches the thyroid plane. Any attempt to separate the cancer from the thyroid should be avoided because it creates an unnecessary risk of R 1 margins. More difficult is decision-making when parathyroid cancer touches the recurrent laryngeal nerve. In case of firm adhesions and a significant suspicion of cancer, the nerve should be sacrificed, and consent for this procedure should be obtained before surgery according to the index of suspicion. Esophageal infiltration is mostly focal and can be resolved with excision of the outer layer of the esophageal muscle with direct repair. None of our patients experienced a leak from this approach, whereas the one patient with infiltration of the full thickness of the esophageal wall and neighboring trachea treated by disc excision experienced a minor salivary leak controlled by drainage alone. Tracheal infiltration forced partial tracheal resection with direct repair in only two of our patients. There was no air-leak complication. In general, it can be stated that surgical morbidity beyond vocal cord palsy is absent or negligible in experienced hands, with discharge from ward care within 24-48 $\mathrm{h}$ after surgery unless hungry bone syndrome poses a therapeutic challenge.

There will be occasions that atypical parathyroid adenoma mimics the intraoperative appearance of parathyroid cancer. Oncologic resection performed on suspicion rather than diagnosis may then lead to unnecessary sacrifice of the recurrent laryngeal nerve. This incident and erring on the side of caution is justified when possibly dealing with a not-so-rare fatal disease.

An important and unsettled question is what should be done if an R1 status is identified for a patient. Most surgeons would be reluctant to perform reoperation at this stage, and data show that reoperation provides limited chances of locoregional disease control. There are no controlled randomized data to demonstrate the benefits of adjuvant radiotherapy, though historic experience demonstrates a likely benefit. ${ }^{4,6,26}$

We agree with Kassahun and Jonas ${ }^{11}$ that diagnostic uncertainty often leads to inadequate initial surgical treatment. We would add that this is often compounded by an attempt to preserve the recurrent laryngeal nerve at preventing nerve palsy, which should under oncologic circumstances not be seen as a "complication." Modern diagnostic work-up allows a reliable preoperative assessment for the risk of parathyroid cancer. The experienced endocrine surgeon will then be in a position to further corroborate this view by intraoperative findings on palpation rather than inspection. A firm, immobile, fixated, or nonshifting mass should invariably be treated as cancerous if the preoperative index of suspicion is high.

In this light, every patient with primary hyperparathyroidism should be evaluated against algorithms elucidating the risk of cancer and should be referred for surgery in tertiary centers if a risk is identified. ${ }^{6}$ Risk assessment might be best achieved through a multidisciplinary team approach for all cases that are not strictly routine.

This study provides evidence that the initial surgical approach determines the fate of the patient. Preoperative suspicion and intraoperative impressions should then instruct the surgeon to perform oncologic surgery in case of doubt. Revision surgery is avoidable and has limited outcome benefit as to cure.

DISCLOSURE The authors have nothing to disclose.

\section{APPENDIX}

See Appendix Tables 4, 5 and 6.

APPENDIX TABLE 4 Clinical presentation of 19 patients with parathyroid cancer

\begin{tabular}{llllll}
\hline $\begin{array}{l}\text { Patient } \\
\text { No. }\end{array}$ & Sex & $\begin{array}{l}\text { Age at } \\
\text { diagnosis } \\
\text { (years) }\end{array}$ & $\begin{array}{l}\text { Preoperative } \\
\text { calcium }^{\mathrm{a}} \mathrm{mM}\end{array}$ & $\begin{array}{l}\text { Preoperative } \\
\text { PTH }^{\mathrm{a}} \mathrm{ng} / \mathrm{L}\end{array}$ & $\begin{array}{l}\text { Size of } \\
\text { lesion } \\
(\mathrm{mm})\end{array}$ \\
\hline 1 & F & 57 & 3.2 & 4.1 & 40 \\
2 & M & 66 & 3.6 & 7.5 & 20 \\
3 & M & 40 & 3.7 & 22.3 & 60 \\
4 & F & 52 & 2.8 & 2.4 & 30 \\
5 & F & 62 & 4.7 & 19.9 & 65 \\
6 & F & 59 & 2.9 & 17.6 & 60 \\
7 & F & 67 & 2.8 & 2.3 & 29 \\
8 & M & 33 & 2.8 & 3.7 & 20 \\
9 & F & 47 & 2.8 & 1.5 & 15 \\
10 & F & 63 & 2.8 & 8.9 & 47 \\
11 & M & 37 & 3.2 & 4.7 & 30 \\
12 & F & 75 & 3.0 & 2.6 & 22 \\
13 & F & 54 & 3.2 & 13.7 & 56 \\
14 & F & 58 & 2.8 & 17.0 & 50 \\
15 & F & 63 & NK & NK & 20 \\
16 & F & 63 & NK & NK & 19 \\
17 & M & 57 & 3.3 & 12.1 & 33 \\
18 & M & 81 & 2.8 & 5.7 & 50 \\
19 & F & 64 & 2.7 & 1.3 & 28 \\
\hline & & & & & \\
\hline
\end{tabular}

Patient 12 was not suspected to have cancer and underwent local excision alone. Patient 15 was operated on in 1996 by another surgeon at the center. Patients 16 to 19 had initial surgery elsewhere

${ }^{a}$ Fold elevated: Calculated as times the upper normal limit of the method used 





APPENDIX TABLE 6 Univariate analysis comparing cohorts undergoing nononcologic and oncologic resection

\begin{tabular}{|c|c|c|c|}
\hline Clinical factor & $\begin{array}{l}\text { Nononcologic } \\
(n=6)\end{array}$ & $\begin{array}{l}\text { Oncologic } \\
(n=13)\end{array}$ & $\chi^{2}(p$ Value \\
\hline \multicolumn{4}{|l|}{ Gender } \\
\hline Male/female & $1 / 5$ & $9 / 4$ & NS \\
\hline \multicolumn{4}{|l|}{ Age (years) } \\
\hline Mean \pm SD & $67.2 \pm 89.0$ & $53.5 \pm 11.1$ & $6.9(0.02)$ \\
\hline Median & 63.5 & 57.0 & \\
\hline Range & $57-81$ & $33-67$ & \\
\hline \multicolumn{4}{|l|}{$\mathrm{PTH}^{\mathrm{a}} \mathrm{ng} / \mathrm{L}$} \\
\hline Mean $\pm \mathrm{SD}$ & $5.4 \pm 4.8$ & $9.7 \pm 7.4$ & NS \\
\hline Median & 4.1 & 7.5 & \\
\hline Range & $1.3-12.1$ & $1.5-22.3$ & \\
\hline \multicolumn{4}{|l|}{$\mathrm{Ca}^{\mathrm{a}} \mathrm{mM}$} \\
\hline Mean \pm SD & $2.9 \pm 0.2$ & $3.2 \pm 0.6$ & NS \\
\hline Median & 2.9 & 2.9 & \\
\hline Range & $2.7-3.3$ & $2.8-4.7$ & \\
\hline \multicolumn{4}{|l|}{ Size of lesion (mm) } \\
\hline Mean $\pm \mathrm{SD}$ & $28.7 \pm 11.7$ & $40.1 \pm 17.3$ & NS \\
\hline Median & 25.0 & 40.0 & \\
\hline Range & $19-50$ & $15.0-65.0$ & \\
\hline \multicolumn{4}{|l|}{ Vascular invasion } \\
\hline Yes/no & $2 / 4$ & $7 / 6$ & NS \\
\hline \multicolumn{4}{|c|}{ Lymph node metastases } \\
\hline Yes/no & 0 & $1 / 12$ & NS \\
\hline \multicolumn{4}{|l|}{ Histology } \\
\hline Low risk/high risk & $4 / 2$ & $6 / 7$ & NS \\
\hline
\end{tabular}

$N S$ not statistically significant

${ }^{\text {a }}$ Fold elevated: Calculated as times the upper normal limit of the method used

\section{REFERENCES}

1. Obara T, Fujimoto Y. Diagnosis and treatment of patients with parathyroid carcinoma: an update and review. World J Surg. 1991;15:738-44.

2. Ruda JM, Hollenbeak CS, Stack BC Jr. A systematic review of the diagnosis and treatment of primary hyperparathyroidism from 1995 to 2003. Otolaryngol Head Neck Surg. 2005;132:359-72.

3. Hundahl SA, Fleming ID, Fremgen AM, Menck HR. Two hundred eighty-six cases of parathyroid carcinoma treated in the US between 1985-1995: a National Cancer Data Base Report. The American College of Surgeons Commission on Cancer and the American Cancer Society. Cancer. 1999;86:538-44.

4. Talat N, Schulte K. Clinical presentation, staging and long-term evolution of parathyroid cancer. Ann Surg Oncol. 2010;17:215674.

5. Harari A, Waring A, Fernandez-Ranvier G, et al. Parathyroid carcinoma: a 43-year outcome and survival analysis. J Clin Endocrinol Metab. 2011;96:3679-86.
6. Schulte KM, Talat N. Diagnosis and management of parathyroid cancer. Nat Rev Endocrinol. 2012;8:612-22.

7. Sidhu PS, Talat N, Patel P, et al. Ultrasound features of malignancy in the preoperative diagnosis of parathyroid cancer: a retrospective analysis of parathyroid tumours larger than $15 \mathrm{~mm}$. Eur Radiol. 2011;21:1865-73.

8. Cavalier E, Daly AF, Betea D, et al. The ratio of parathyroid hormone as measured by third- and second-generation assays as a marker for parathyroid carcinoma. J Clin Endocrinol Metab. 2010;95:3745-9.

9. Caron P, Maiza JC, Renaud C, et al. High third generation/second generation PTH ratio in a patient with parathyroid carcinoma: clinical utility of third generation/second generation PTH ratio in patients with primary hyperparathyroidism. Clin Endocrinol (Oxf). 2009;70:533-8.

10. Rubin MR, Silverberg SJ, D'Amour P, et al. An N-terminal molecular form of parathyroid hormone $(\mathrm{PTH})$ distinct from $\mathrm{hPTH}(1 \mathrm{84})$ is overproduced in parathyroid carcinoma. Clin Chem. 2007;53:1470-6.

11. Kassahun WT, Jonas S. Focus on parathyroid carcinoma. Int $J$ Surg. 2011;9:13-9.

12. Schulte KM, Gill A, Barczinski M, et al. Classification of parathyroid cancer. Ann Surg Oncol. 2012;19:2620-8.

13. Schulte KM, Talat N, Miell J, et al. Lymph node involvement and surgical approach in parathyroid cancer. World $J$ Surg. 2010;34:2611-20.

14. DeLellis RA, Lloyd RV, Heitz PU, Eng C. Pathology and genetics of tumours of endocrine organs (WHO classification). Lyon: International Agency for Research on Cancer; 2004.

15. Busaidy NL, Jimenez C, Habra MA, et al. Parathyroid carcinoma: a 22-year experience. Head Neck. 2004;26:716-26.

16. Kebebew E. Parathyroid carcinoma. Curr Treat Options Oncol. 2001;2:347-54.

17. Montenegro FL, Tavares MR, Durazzo MD, et al. Clinical suspicion and parathyroid carcinoma management. Sao Paulo Med J. 2006;124:42-4.

18. Lee PK, Jarosek SL, Virnig BA, et al. Trends in the incidence and treatment of parathyroid cancer in the United States. Cancer. 2007;109:1736-41.

19. Robbins KT. Classification of neck dissection: current concepts and future considerations. Otolaryngol Clin North Am. 1998;31:639-55.

20. Wang CA, Gaz RD. Natural history of parathyroid carcinoma. Diagnosis, treatment, and results. Am J Surg. 1985;149:522-7.

21. Iihara M, Okamoto T, Suzuki R, et al. Functional parathyroid carcinoma: long-term treatment outcome and risk factor analysis. Surgery. 2007;142:936-43; discussion 943e1.

22. Kebebew E, Arici C, Duh QY, Clark OH. Localization and reoperation results for persistent and recurrent parathyroid carcinoma. Arch Surg. 2001;136:878-85.

23. Cordeiro AC, Montenegro FL, Kulcsar MA, et al. Parathyroid carcinoma. Am J Surg. 1998;175:52-5.

24. Ippolito G, Palazzo FF, Sebag F, et al. Intraoperative diagnosis and treatment of parathyroid cancer and atypical parathyroid adenoma. Br J Surg. 2007;94:566-70.

25. Fernandez-Ranvier GG, Khanafshar E, Jensen K, et al. Parathyroid carcinoma, atypical parathyroid adenoma, or parathyromatosis? Cancer. 2007;110:255-64.

26. Munson ND, Foote RL, Northcutt RC, et al. Parathyroid carcinoma: is there a role for adjuvant radiation therapy? Cancer. 2003;98:2378-84 